\title{
Activation processes of highly ordered carbon nanofibers in the oxidative dehydrogenation of ethylbenzene
}

\author{
J. J. Delgado ${ }^{\mathrm{a}}$, X.-W. Chen ${ }^{\mathrm{b}}$, B. Frank ${ }^{\mathrm{a}}$, D. S. Su ${ }^{\mathrm{a}, *}$, R. Schlögl ${ }^{\mathrm{a}}$ \\ ${ }^{a}$ Department of Inorganic Chemistry, Fritz Haber Institute of the Max Planck Society, Faradayweg 4-6, D-14195 \\ Berlin, Germany \\ ${ }^{\mathrm{b}}$ Departamento de Ciencia de los Materiales, Ingeniería Metalúrgica y Química Inorgánica, Facultad de Ciencias, \\ Universidad de Cádiz, Campus Río San Pedro, Puerto Real (Cádiz), E-11510, Spain
}

${ }^{*}$ Corresponding author: e-mail dangsheng@,fhi-berlin.mpg.de,

Article first published online: 22 November 2011

\begin{abstract}
Highly graphitized multiwalled carbon nanofibers (CNFs) were used as a carbon-based model catalyst to study the oxidative dehydrogenation (ODH) of ethylbenzene. Their stability as well as the evolution of catalytic performance as well as structural and textural properties under robust operation conditions were studied. The catalyst was characterized by TEM, TPO, XPS, and $\mathrm{N}_{2}$ physisorption techniques. Highly ordered CNFs provide a low initial catalytic activity owing to the low degree of surface functionalization. The rate of ethylbenzene conversion increases by factor of 5 as the catalyst is exposed to the reaction conditions at $475^{\circ} \mathrm{C}$ for a period of $30 \mathrm{~h}$ time on stream. A similar catalytic performance is obtained after short-term oxidation treatment of the pristine CNFs. The in-situ formation of surface defects is attributed to the activation of the catalyst, whereas the generation of an active carbonaceous deposit on the catalyst surface is found to be less relevant.
\end{abstract}

Keywords: Carbon nanofibers, Carbocatalysis, Styrene, Coke, Defects

\section{Introduction}

The dehydrogenation of ethylbenzene is considered as one of the most important industrial reactions since produced styrene is used for the production of a wide variety of polymers and copolymers [1]. The ODH of ethylbenzene to styrene is postulated as an attractive solution to overcome the disadvantages of non-oxidative catalytic dehydrogenation of ethylbenzene, such as the thermodynamic limitation and extreme operation conditions [2,3]. Among the materials that have been investigated as catalysts for ODH of ethylbenzene, different carbonaceous materials, e.g., activated carbon, carbon nano-filaments, and onionlike carbon, have recently attracted attention [4-6]. Hierarchical structures based on carbon nanotubes (CNTs) and CNFs supported on activated carbon and carbon felts exhibit a high catalytic activity for ODH of ethylbenzene. The low pressure drop along the reactor filled with catalytic materials formulated in such a way makes them promising candidates for industrial applications [7].

The nature and the amount of basic oxygen groups, i.e., ketones and quinones, as the red-ox active sites have been pointed out to control the catalytic activity [4]. Carbon with less ordered structure deactivates rapidly with time on stream, while CNTs with their graphitic structure and low porosity are more stable under robust operation condition [8-10]. However, it was shown that the increased chemical and structural stability of CNTs calcined at elevated temperature negatively influences the activity of the sample $[11,12]$. In the present work highly ordered CNFs were used as model catalyst to determine and interpret the evolution the catalytic performance and get some additional information regarding the active sites and the catalyst activation during the reaction. Using elemental carbon as a catalyst for oxidation reactions, a pronounced initial (de)activation profile is generally observed, which is related to coke deposition in micropores [13], surface restructuring [9], and equilibration of surface oxygen groups [1417]. The present study focuses on different methods of surface treatment, which are expected to result in different states of activated surfaces with different catalytic performances. 


\section{Experimental}

Commercial CNFs (PR24 HHT) used in the present work were purchased from Pyrograf Products Inc. Some basic physico-chemical characterization is given elsewhere $[11,18]$. The material was synthesized by chemical vapour deposition and subsequently heat-treated at $3000{ }^{\circ} \mathrm{C}$ under $\mathrm{N}_{2}$ by the provider. The CNF powder was directly used in the catalytic reaction or post-treated in an air flow $(60 \mathrm{~mL}$ $\left.\min ^{-1}\right)$ at different temperatures $\left(475-620^{\circ} \mathrm{C}\right)$ and different treatment times $(1-50 \mathrm{~h})$.

X-ray photoelectron spectroscopy (XPS) was performed with a Kratos Axis Ultra DLD spectrometer using a monochromated Al K $\alpha$ X-ray source ( $h v=1486.6$ eV). Prior to peak fitting, Shirley backgrounds [19] were subtracted. The peak areas were normalized with the theoretical cross-sections [20] to obtain the relative surface compositions. Samples were characterized by $\mathrm{N}_{2}$ physisorption at the temperature of liquid $\mathrm{N}_{2}\left(-196{ }^{\circ} \mathrm{C}\right)$ using a Micrometeritics ASAP 2010 device. The samples were outgassed for $2 \mathrm{~h}$ at $120^{\circ} \mathrm{C}$ before the measurements. The surface area was calculated by using the BrunauerEmmett-Teller (BET) method [21] based on the adsorption data in the relative pressure $\left(p / p_{0}\right)$ range of $0.05-0.20$. Temperature-programmed oxidation (TPO, 20 vol.\% $\mathrm{O}_{2}$ in $\mathrm{Ar}, 5 \mathrm{~K} \mathrm{~min}^{-1}$ ) was performed in the catalytic set-up described below. The effluent gas was analyzed by a mass spectrometer (Pfeiffer Thermostar). Transmission electron microscopy (TEM) analysis was performed with a Phillips CM200 FEG field-emission gun electron microscope operating at an accelerating voltage of $200 \mathrm{kV}$.

Catalytic tests were performed in a set-up described elsewhere [11]. The ODH of ethylbenzene was performed at $400{ }^{\circ} \mathrm{C}$ and at atmospheric pressure. $60 \mathrm{mg}$ of pelletized catalyst particles $(100-200 \mu \mathrm{m})$ were diluted with $\mathrm{SiC}$ particles of the same size fraction (1:35 by weight) and placed between two quartz wool plugs in the isothermal zone of the quartz tubular reactor. The reactant flow was a mixture of 2.6 vol.\% EB and oxygen (O/EB ratio of 2.6:1) diluted in $\mathrm{He}$ with a the total space velocity of $5000 \mathrm{ml} \mathrm{g}^{-1}$ $\mathrm{h}^{-1}$. No steam was added to the reactor.

\section{Results and discussion}

The evolution of the catalytic performance of the fresh CNF catalyst sample at different temperatures is shown in Fig. 1a. The initial activity at the lowest temperature is quite poor, although a high selectivity is obtained. A small amount of surface defects and oxygenated species have been previously reported to be the origin of this initial catalytic performance [11]. The catalytic activity slightly increases by increasing the temperature from 400 to $450^{\circ} \mathrm{C}$, however, the selectivity to styrene decreases from almost 100 to $75 \%$. The high selectivity at a low level of conversion as well as the decay of styrene selectivity at elevated ethylbenzene conversion
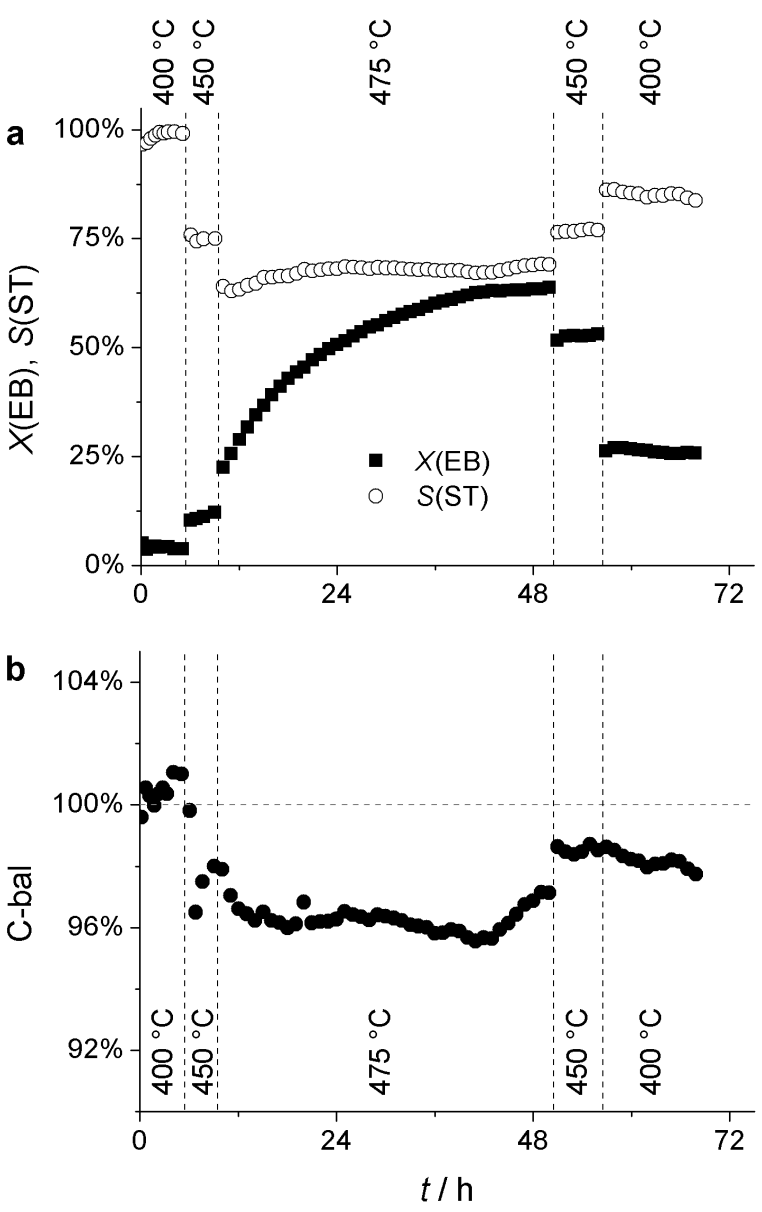

Fig. 1. (a) Conversion of ethylbenzene (EB), selectivity to styrene (ST), and (b) carbon balance as a function of time on stream with changing reactor temperature. $60 \mathrm{mg}$ catalyst, 2.6 vol.\% $\mathrm{EB}$ and 6.8 vol. $\% \mathrm{O}_{2}$ in $\mathrm{He}, 5000 \mathrm{ml} \mathrm{g}^{-1} \mathrm{~h}^{-1}$.

might be explained by the Wheeler type III reaction network [22] consisting of ethylbenzene ODH as the target reaction followed by secondary combustion of produced styrene. The absence of pronounced equilibration periods indicates a stable state of the catalytically active carbon surface even at this low degree of surface functionalization. More dramatic changes can be observed at the further increase of the reaction temperature to $475{ }^{\circ} \mathrm{C}$. Within a long activation period of about $30 \mathrm{~h}$ the conversion of ethylbenzene increases from 25 to $64 \%$. Here, the selectivity to styrene initially drops to $63 \%$, however, approaches $70 \%$ with time on stream (TOS) at the high reaction temperature. Fig. $1 \mathrm{~b}$ shows the corresponding carbon balance during this experiment. During the hightemperature activation process, the total carbon content of the stream is significantly below the initial concentration, which indicates coke formation on the catalyst surface. As the activation process is finished and the catalytic performance approaches steady state conditions, i.e., after $40 \mathrm{~h}$ TOS, the adsorption of carbonaceous material on the catalyst surface decreases. After the activation at $475^{\circ} \mathrm{C}$, the catalytic activity of the CNF sample at 450 and $400{ }^{\circ} \mathrm{C}$ 


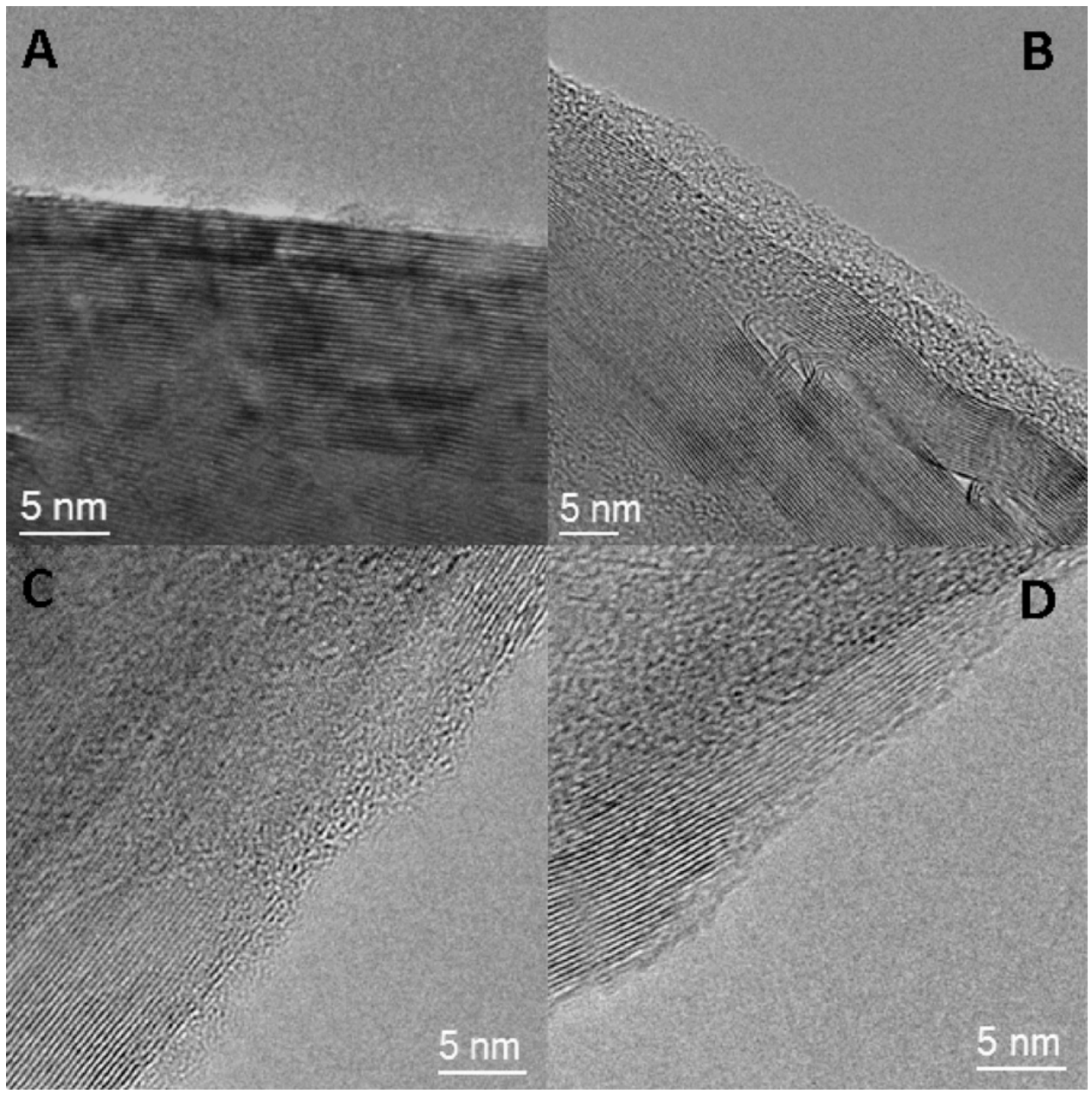

Fig. 2. HRTEM images of (a) the fresh CNF catalyst sample and (b-d) after catalyzing the ODH of ethylbenzene at $475^{\circ} \mathrm{C}$.

is by factor of 5 higher than on the non-activated CNF catalyst. More importantly, similar styrene selectivities of $75 \%$ obtained at $450^{\circ} \mathrm{C}$ before and after the surface activation highlight the drastic improvement of the catalyst surface in terms of selective activation of ethylbenzene. The carbon balances of $\sim 98 \%$ obtained over the activated catalysts at lower temperatures might be related (i) to the higher activity of the catalyst surface being more susceptible to coke deposition or (ii) to the higher amount of styrene in the gas phase as a result of higher reaction rates obtained. Besides oxidative attack of the reactant molecules, styrene also suffers degradation by polymerization on the catalyst surface.

The interpretation of the catalytic results is supported by HRTEM analysis of the catalyst samples before and after reaction. Fig. 2a shows the highly organized structure of the pristine CNF sample, which it is in good concordance with its low catalytic activity [11]. Residual amorphous structures are visible on the CNF surface; the bulk, however, is well crystallized and almost free of defects. The characterization of the used catalyst after the activation procedure shown in Fig. 1 reveals the presence of an amorphous carbon layer on some areas of the catalyst surface (Fig. 2b). This layer is approx. 1-2 nm thick and covers a significant part of the outer CNF surface. In addition, defective parts of the surface without significant coating by disordered carbon debris can be observed (Figs. $2 \mathrm{c}$ and $\mathrm{d}$ ), which might be produced by partial combustion of the CNTs during the reaction. These defect sites are potential candidates to anchor different oxygenated species such as quinoidic carbonyl groups, which are recognized as active phase for this reaction $[4,23,24]$. However, it is reported that the formation of a surface coke layer with a high concentration of oxygenated functional groups improves the catalytic activity of an alumina catalyst $[25,26]$. In this view the high-temperature activation of the CNF catalyst under the ethylbenzene ODH feed gas gives no clear answer whether the active sites for the reaction are attached to defects on the CNF surface or to the coke layer formed during activation.

The burn-off profiles obtained from TPO of the fresh $\mathrm{CNF}$ sample and the catalyst after reaction give additional information regarding the nature and amount of coke formed (Fig. 3). Two single peaks in the TPO profiles of $\mathrm{CO}$ and $\mathrm{CO}_{2}$, respectively, are observed for the pristine $\mathrm{CNFs}$. Both have onsets at around $620-630^{\circ} \mathrm{C}$ and maxima 

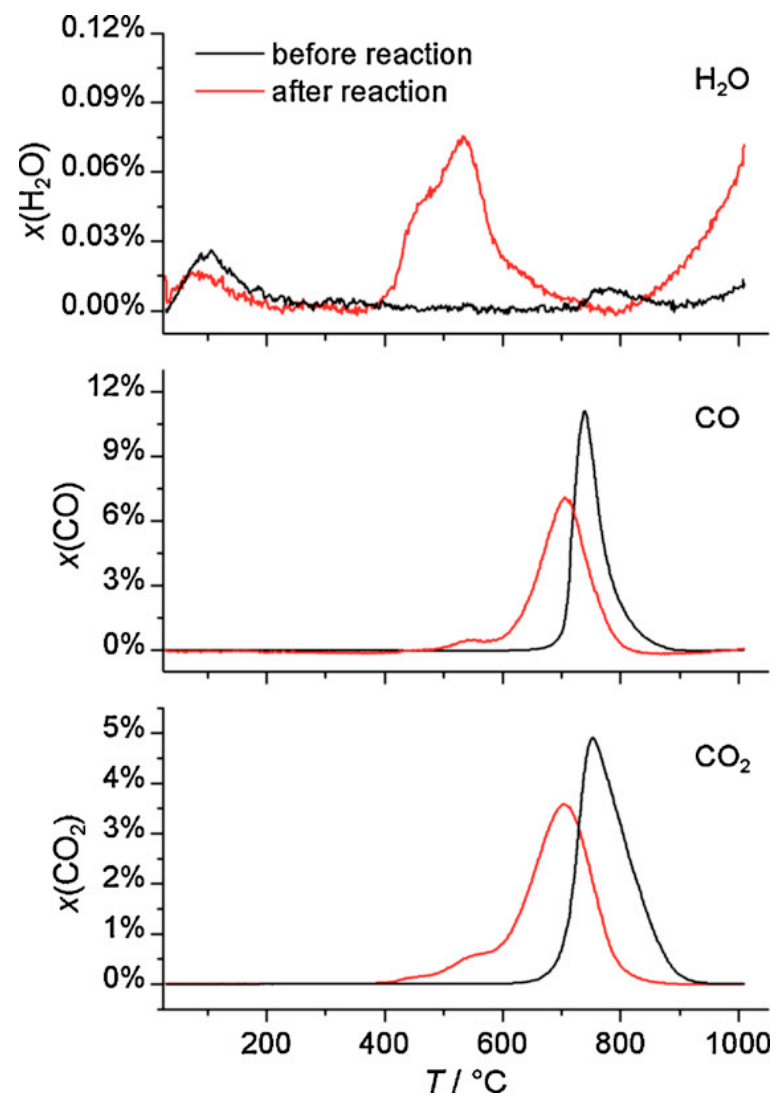

Fig. 3. Profiles of $\mathrm{H}_{2} \mathrm{O}, \mathrm{CO}$, and $\mathrm{CO}_{2}$ during $\mathrm{TPO}$ analysis of fresh and used catalysts.

at $740-750^{\circ} \mathrm{C}$. Their smooth shapes indicate steady burn-off and chemical similarity of $\mathrm{C}$ atoms, i.e., confirm the high degree of crystallization and structural homogeneity of the pristine CNF sample, which is almost free of carbon debris on the surface. The low resolution of the $\mathrm{H}_{2} \mathrm{O}$ profile is owing to the low degree of surface functionalization in general and the low amount of $\mathrm{H}$ containing surface functional groups such as carboxylic acids or phenols in particular. Two small peaks are visible in the profile, i.e., low temperature desorption of physically adsorbed water at $<200^{\circ} \mathrm{C}$ and water getting released by combustion of phenols at around $800{ }^{\circ} \mathrm{C}$. The TPO profiles of the used $\mathrm{CNF}$ catalysts are more complex. One additional peak in the $\mathrm{CO}$ profile $\left(545^{\circ} \mathrm{C}\right)$ and two additional peaks in the $\mathrm{CO}_{2}$ profile $\left(450\right.$ and $550^{\circ} \mathrm{C}$ ) can most likely be assigned to the presence of an oxygen- and hydrogen-rich coke layer generated by hydrocarbon adsorption. This assignment is confirmed by the $\mathrm{H}_{2} \mathrm{O}$ profile showing a major peak at 400$600^{\circ} \mathrm{C}$ besides the small peak at $<200^{\circ} \mathrm{C}$ due to physical desorption. The mass fraction of $\sim 10 \%$ of $\mathrm{CO}$ and $\mathrm{CO}_{2}$ medium temperature features indicates that they rather result from combustion of matter than from decomposition of surface functional groups. However, the most evident change in $\mathrm{CO}$ and $\mathrm{CO}_{2}$ profiles is the shift of the main peaks to lower temperatures. The absence of $\mathrm{H}_{2} \mathrm{O}$ being released in significant quantity indicates the combustion of hydrogen-free carbon matrix. The drastic decrease of burn- off onset and maximum temperatures can be understood in a way that surface defects created during catalytic reaction act as hot spots to initialize the combustion of the graphitic host structure [27].

In order to separate the contributions of surface defects and coke formation to the overall catalytic activity, the CNF catalyst was initially activated by catalytic reaction at $475{ }^{\circ} \mathrm{C}$ for $35 \mathrm{~h}$. The catalytic performance after lowering the reaction temperature to $400^{\circ} \mathrm{C}$ is shown in Fig. 4 and very similar to the data shown in Fig. 1. After $10 \mathrm{~h}$ TOS the deposited coke layer was subsequently removed by stopping the ethylbenzene flow and changing the reaction mixture to $6.8 \% \mathrm{O}_{2}$ in $\mathrm{He}$ at the elevated temperature of $500{ }^{\circ} \mathrm{C}$. TPO profiles (Fig. 3) suggest that the $\mathrm{CNF}$ host structure remains untouched after this treatment. The $\mathrm{CO}$ and $\mathrm{CO}_{2}$ production by coke combustion was followed by gas chromatography. After 45 min no $\mathrm{CO}_{\mathrm{x}}$ was observed in the stream, however, the oxidizing conditions were kept for $1.5 \mathrm{~h}$ in total. HRTEM analysis confirms the complete removal of the coke layer. After this treatment, the catalytic activity using the standard feed composition for ODH of ethylbenzene at $400^{\circ} \mathrm{C}$ was determined. As compared to the initial coke-activated state of the catalyst the conversion drops from 31 to $23 \%$ after the elimination of the coke. This suggests that the catalyst activation process would be related in majority to the formation of defects on the outer CNF surface rather than on an active coke-layer. The activity loss observed after coke removal would not necessarily indicate some residual activity of coke, as it must be noted that parts of active quinone/hydroquinone groups on surface defects may likely be destroyed during the oxidation treatment.

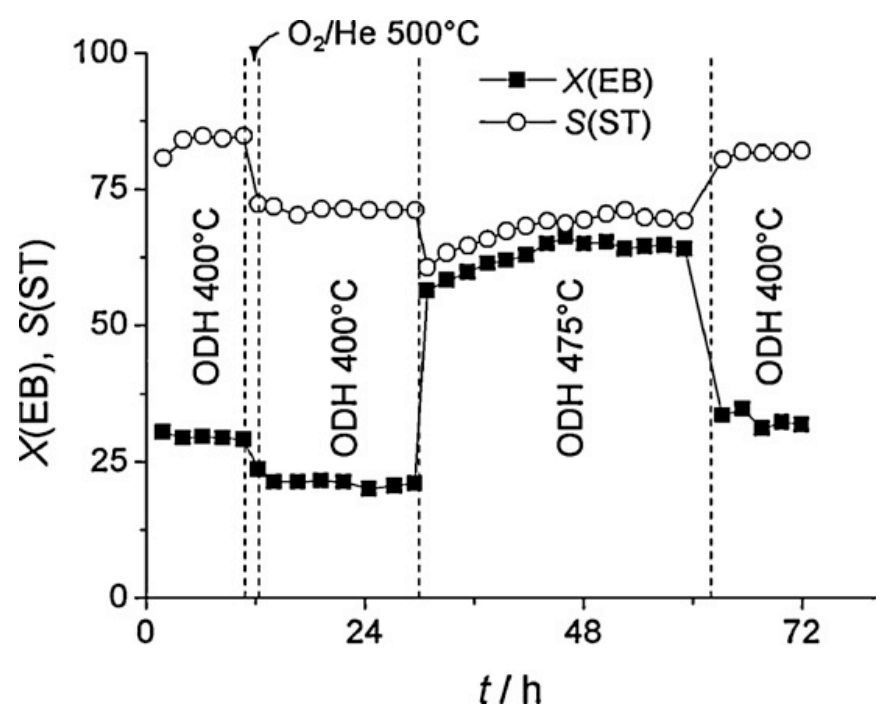

Fig. 4. Ethylbenzene conversion and styrene selectivity of an activated CNF catalyst as a function of time on stream with changing reaction conditions. $60 \mathrm{mg}$ catalyst, 2.6 vol.\% $\mathrm{EB}$ and 6.8 vol. $\% \mathrm{O}_{2}$ in $\mathrm{He}, 5000 \mathrm{ml} \mathrm{g}^{-1} \mathrm{~h}^{-1}$. 


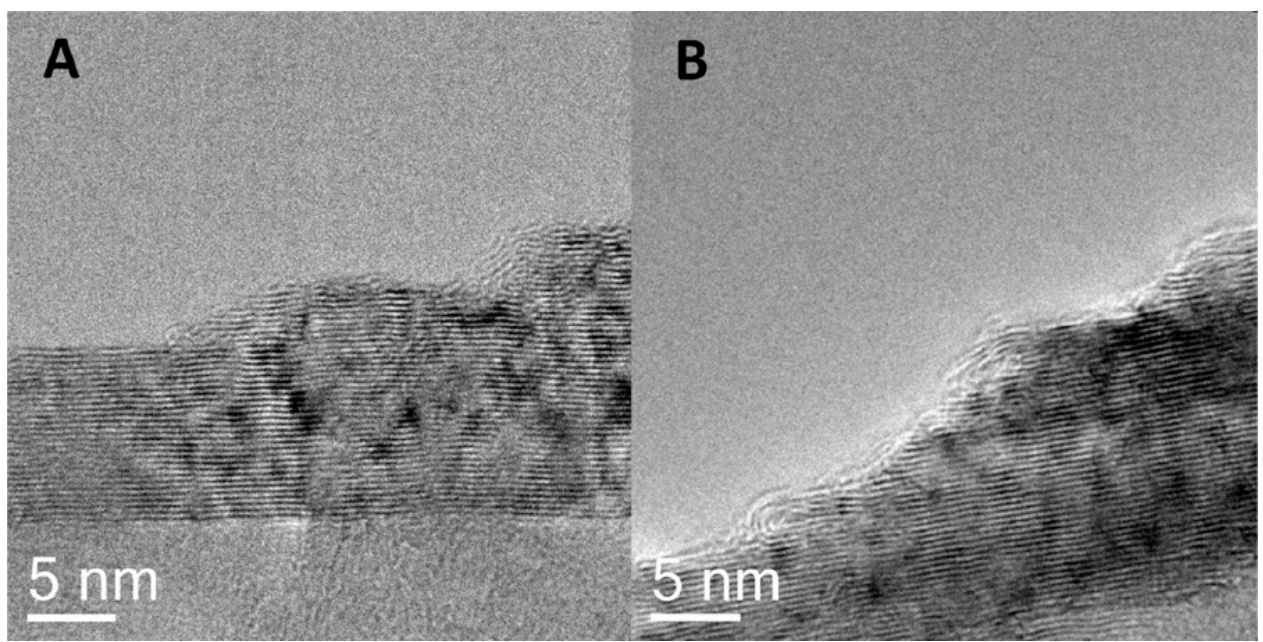

Fig. 5. HRTEM images of the CNF sample after treatment in air (a) for $50 \mathrm{~h}$ at $475{ }^{\circ} \mathrm{C}$ and (b) for $5 \mathrm{~h}$ at $620^{\circ} \mathrm{C}$.

The catalyst was subsequently "re-activated" by rising the reaction temperature again to $475{ }^{\circ} \mathrm{C}$. The observed induction period is shorter than for the pristine CNFs (Fig. 1), however, the same final catalytic performance is approached. The shorter induction period again can be related with the formation of catalytically active surface defects and the reduced length of the induction period can be explained by the higher amount of surface defects on the treated CNF sample as compared to the pristine CNFs. Surface defects act as a preferential point of attack for hydrocarbon molecules to initiate their degradation in terms of catalyst coking. The activity at 400 ${ }^{\circ} \mathrm{C}$ demonstrates that the catalyst is completely regenerated. This cycle was repeated giving similar results. It should be pointed out that the duration of this experiment was up to $200 \mathrm{~h}$ and no significant catalyst deactivation was observed.

Ultimately, with the purpose to confirm the contribution of surface defects to the catalytic activity, the fresh CNF sample was treated in an air flow at different temperatures. Table 1 includes the weight loss, as well as the textural properties of the samples. Even by treating the sample at $475{ }^{\circ} \mathrm{C}$, the sample is partially oxidized and after $50 \mathrm{~h}$ a weight loss of $19.9 \%$ is found. In parallel, an increase of the surface area is observed, which is consistent with the formation of edges and kinks during the combustion. HRTEM confirms the presence of these sites (Fig. 5), which are structurally similar to those observed in the sample after reaction (Fig. 2d). Similar HRTEM results were obtained for all the samples, although the weight loss and the specific surface area were different. Table 1 also contains the conversions of $\mathrm{EB}$, product selectivities, as well as the areal consumption rate of EB measured on the air-oxidized CNF samples at $400{ }^{\circ} \mathrm{C}$. The results appear to be implying that the activity increases with the specific surface area and is independent from the conditions of oxidation. In fact, similar catalytic performances in terms of areal rates of ethylbenzene conversion were obtained for all the calcined CNFs. Styrene selectivities range from 77 to $85.2 \%$, however, depend on the level of ethylbenzene conversion obtained over the catalyst samples. These experiments clearly prove that surface defects are responsible for the catalytic activity of carbonaceous catalysts in the $\mathrm{ODH}$ of ethylbenzene rather than oxygen functionalities abundantly present in the coke layer formed under reaction conditions.

The differences in surface chemical groups of $\mathrm{ODH}-$ activated $\left(50 \mathrm{~h}\right.$ at $\left.475^{\circ} \mathrm{C}\right)$ and $\mathrm{O}_{2}$-activated $\left(4 \mathrm{~h}\right.$ at $\left.500^{\circ} \mathrm{C}\right)$ $\mathrm{CNF}$ surfaces were finally highlighted by XPS analysis (Fig. 6). Band assignments are based on literature [10]. The pristine CNF give rise to weakly pronounced bands at 532.1 and $531.3 \mathrm{eV}$ which can be assigned to hydroxyls, ethers, and $\mathrm{C}=\mathrm{O}$ double bonds in esters and anhydrides as well as $\mathrm{C}=\mathrm{O}$ double bonds in ketones and quinones, respectively. The total oxygen drastically increases upon activation by both methods and a third very strongly

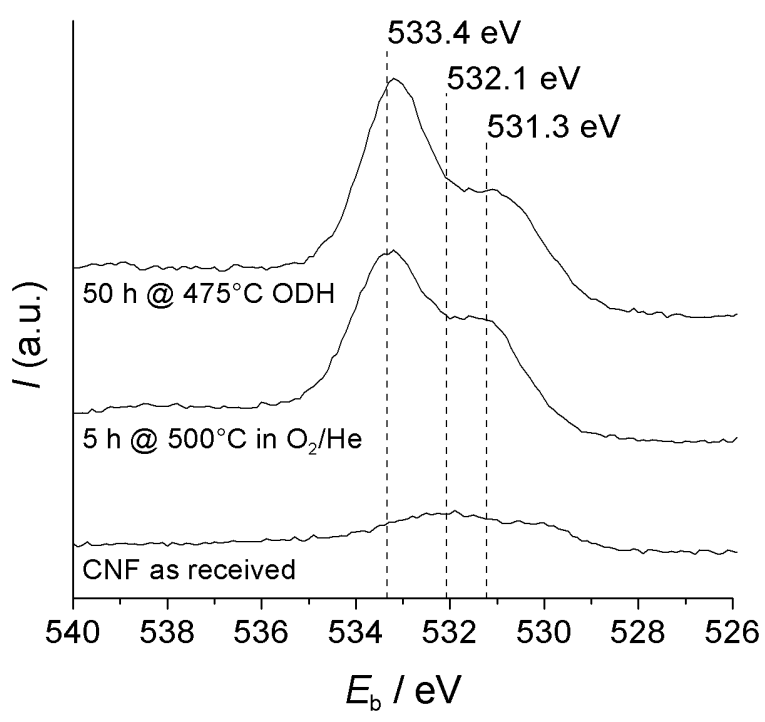

Fig. 6. O1s range of the XPS analysis of fresh and activated CNF catalysts 
Table 1. Mass loss, specific surface areas and catalytic performances of CNF samples after activation by oxidation in air at different conditions.

\begin{tabular}{|c|c|c|c|c|c|c|c|}
\hline \multirow[t]{2}{*}{ Air treatment } & \multirow[t]{2}{*}{$\Delta m(\%)$} & \multirow[t]{2}{*}{$S_{\text {BET }}\left(\mathrm{m}^{2} \mathrm{~g}^{-1}\right)$} & \multirow[t]{2}{*}{$X(\%)$} & \multicolumn{3}{|l|}{$S(\%)$} & \multirow{2}{*}{$\begin{array}{l}r_{\mathrm{EB}} \\
\left(\mu \mathrm{mol} \mathrm{m}^{-2} \mathrm{~min}^{-1}\right)\end{array}$} \\
\hline & & & & ST & $\mathrm{CO}$ & $\mathrm{CO}_{2}$ & \\
\hline- & 0.0 & 31.0 & 4.4 & 95.3 & 2.3 & 2.5 & 0.13 \\
\hline $50 \mathrm{~h} @ 475^{\circ} \mathrm{C}$ & 19.9 & 99.0 & 21.5 & 80.8 & 7.2 & 11.8 & 0.20 \\
\hline $1 \mathrm{~h} @ 605^{\circ} \mathrm{C}$ & 4.2 & 43.8 & 10.7 & 83.4 & 6.5 & 10.0 & 0.22 \\
\hline $1 \mathrm{~h} @ 620^{\circ} \mathrm{C}$ & 7.6 & 58.8 & 14.9 & 85.2 & 6.5 & 9.0 & 0.23 \\
\hline $5 \mathrm{~h} @ 620^{\circ} \mathrm{C}$ & 64.0 & 91.0 & 21.0 & 77.0 & 8.0 & 15.0 & 0.21 \\
\hline
\end{tabular}

pronounced band at $533.4 \mathrm{eV}$ arises. This band can be assigned to $\mathrm{C}-\mathrm{O}$ single bonds in esters, anhydrides, and carboxylic groups.

It turns out that both methods of catalyst activation result in a variety of different oxygen surface species with very similar fractional distribution. On both surfaces, the electrophilic oxygen groups with high $\mathrm{C}-\mathrm{O}$ binding energies are dominating, which can be related to combustion processes of adsorbed hydrocarbons, coke, and the CNF host. The corresponding peak at $533.4 \mathrm{eV}$ is more pronounced on the "coked" catalyst sample, which is easy to understand in view of the high degree of functionalization and low thermal stability of the disordered carbon debris. Ketonic and quinoidic $\mathrm{C}=\mathrm{O}$ functionalities are present in similar amounts, in good agreement with similar catalytic activities in the ODH of ethylbenzene.

\section{Conclusions}

The in-situ activation of highly ordered CNFs as model catalysts for the ODH of ethylbenzene can be performed at mild operation conditions. A highly active and robust catalyst under operation conditions is obtained. The catalyst

\section{References}

[1] D. James, in:, Ullmann's Encyclopedia of Industrial Chemistry, 5th Ed., Wiley VCH, 1994, pp. 329.

[2] F. Cavani, F. Trifirò, Appl. Catal. A 133 (1995) 219-239.

[3] A. Guerrero-Ruiz, I. Rodríguez-Ramos, Carbon 32 (1994) 23-29.

[4] M.F.R. Pereira, J.J.M. Órfão, J.L. Figueiredo, Appl. Catal. A 184 (1999) 153-160.

[5] G. Mestl, N.I. Maksimova, N. Keller, V.V. Roddatis, R. Schlögl, Angew. Chem. Int. Ed. 40 (2001) 2066-2068.

[6] F. Rodríguez-Reinoso, Carbon 36 (1998) 159-175.

[7] J.J. Delgado, X.W. Chen, D.S. Su, S.B.A. Hamid, R. Schlögl, J. Nanosci. Nanotechnol. 7 (2007) 3495-3501.

[8] D.S. Su, N. Maksimova, J.J. Delgado, N. Keller, G. Mestl, M.J. Ledoux, R. Schlögl, Catal. Today 102-103 (2005) 110114.

[9] J. Zhang, D.S. Su, A. Zhang, D. Wang, R. Schlögl, C. Hébert, Angew. Chem. Int. Ed. 46 (2007) 7319-7323.

[10] B. Frank, A. Rinaldi, R. Blume, R. Schlögl, D.S. Su, Chem. Mater. 22 (2010) 4462-4470. activity is mainly related to the defect formation on the catalyst surface, although from this study it cannot be completely excluded that the formation of coke weakly contributes to the performance. According to our results, the formed coke layer can be easily burned under operation conditions although the equilibrium is observed at the steady state. This opens up an alternative activation process for the CNF catalyst, namely the controlled oxidation with air. Surface chemical analyses and the catalytic performance in the ODH of ethylbenzene show that a similar state of the surface is achieved by this facile procedure.

\section{Acknowledgements}

This project is financially supported by the ENERCHEM project of the Max Planck Society. The authors thank G. Lorentz and J.P. Tessonnier for assistance on experiments.

[11] J.J. Delgado, X. Chen, J.P. Tessonnier, M.E. Schuster, E. Del Rio, R. Schlögl, D.S. Su, Catal. Today 150 (2010) 49-54.

[12] A. Rinaldi, J. Zhang, B. Frank, D.S. Su, S.B. Abd Hamid, R. Schlögl, ChemSusChem 3 (2010) 254-260.

[13] T.G. Alkhazov, A.E. Lisovskii, T.K. Gulakhmedova, React. Kinet. Catal. Lett. 12 (1979) 189-193.

[14] B. Frank, J. Zhang, R. Blume, R. Schlögl, D.S. Su, Angew. Chem. Int. Ed. 48 (2009) 6913-6917.

[15] B. Frank, M. Morassutto, R. Schomäcker, R. Schlögl, D.S. Su, ChemCatChem 2 (2010) 644-648.

[16] J. Zhang, X. Liu, R. Blume, A. Zhang, R. Schlögl, D.S. Su, Science 322 (2008) 73-77.

[17] B. Frank, R. Blume, A. Rinaldi, A. Trunschke, R. Schlögl, Angew. Chem. Int. Ed. (2011) DOI: 10.1002/anie.201103340.

[18] J.-P. Tessonnier, D. Rosenthal, T.W. Hansen, C. Hess, M.E. Schuster, R. Blume, F. Girgsdies, N. Pfänder, O. Timpe, D.S. Su, R. Schlögl, Carbon 47 (2009) 1779-1798.

[19] D.A. Shirley, Phys. Rev. B 5 (1972) 4709-4714. 
[20] J.H. Scofield, J. Electron. Spectrosc. Relat. Phenom. 8 (1976) 129-137.

[21] S. Brunauer, P.H. Emmett, E. Teller, J. Am. Chem. Soc. 60 (1938) 309-319.

[22] A. Wheeler, Adv. Catal. 3 (1951) 249-327.

[23] N. Keller, N.I. Maksimova, V.V. Roddatis, M. Schur, G. Mestl, Y.V. Butenko, V.L. Kuznetsov, R. Schlögl, Angew. Chem. Int. Ed. 41 (2002) 1885-1888.
[24] J. Zhang, X. Wang, Q. Su, L. Zhi, A. Thomas, X. Feng, D.S. Su, R. Schlögl, K. Müllen, J. Am. Chem. Soc. 131 (2009) 11296-11297.

[25] L.E. Cadus, L.A. Arrua, O.F. Gorriz, J.B. Rivarola, Ind. Eng. Chem. Res. 27 (1988) 2241-2246.

[26] L.E. Cadus, O.F. Gorriz, J.B. Rivarola, Ind. Eng. Chem. Res. 29 (1990) 1143-1146.

[27] A. Rinaldi, B. Frank, D.S. Su, S.B.A. Hamid, R. Schlögl, Chem. Mater. 23 (2011) 926-928. 